\title{
Developing of the Aluminum Alloy Solid State Bonding Method in Atmosphere Using High Frequency Induction Heating and Ultrasonic Vibration
}

\author{
Tomoji Osada ${ }^{1, *}, K^{, i j i}$ Sonoya ${ }^{2}$, Takeyuki Abe $^{2}$, Masanobu Nakamura $^{2}$ \\ ${ }^{1}$ Nippon Thermonics Co., Ltd., Japan \\ ${ }^{2}$ Department of Mechanical System Engineering, University of Yamanashi, Japan
}

Copyright $(\mathcal{C} 2016$ by authors, all rights reserved. Authors agree that this article remains permanently open access under the terms of the Creative Commons Attribution License 4.0 International License

\begin{abstract}
Consumption of aluminum alloys is increasing in order to improve the environmental performance. The aim of this research is to develop a technique to bond aluminum within an atmosphere in a short amount of time and with minimal deformations. In order to accomplish this, the bonding was carried out via use of a metal insert and ultrasonic vibration. Bonding employing the insert metal resulted in a weakened bond due to the generation of an oxide layer on the bonding surface which impeded a bond forming between the metals. The addition of ultrasonic vibration resulted in a stronger overall bond than that created without ultrasonic vibration. This is due to the vibration breaking up the oxide surface, inducing plastic flow at the bond interface.
\end{abstract}

Keywords Aluminum Alloy, Solid State Bonding, Atmosphere, High Frequency Induction Heating, Ultrasonic Vibration

\section{Introduction}

The need for lighter materials has grown due to the demand for improved fuel economy and energy efficiency, resulting in greater use of aluminum alloys. This has led to increasing needs for aluminum alloy bonding. However, due to the fact that they develop strong oxide layers in atmosphere and aluminum's specific mechanical and thermophysical properties, aluminum alloys are widely regarded as difficult materials to work with ${ }^{1)}$. Friction-churning bond technology has seen widespread implementation in recent years, but this method and its requirements and limitations mean that it is difficult to employ with parts with precise dimensions and/or complicated designs. For parts such as these, solid-phase welding via vacuum diffusion is employed. The drawbacks of this welding technique are the large size of the required equipment and the long amount of time it requires.

Hence the goal of this research: to bond difficulty to work with aluminum alloys in atmosphere in a short amount of time with minimal defects. To achieve this, bonding was carried out by using a metal insert and ultrasonic vibration.

\section{Test Equipment and Experimental Methods}

\subsection{Test Materials}

The specific aluminum alloys used were A1070-H112, A5052-H34 and A6061-T6 (temper designations are omitted hereafter). Each cylinder had a diameter of $20 \mathrm{~mm}$ and a length of $100 \mathrm{~mm}$. The chemical composition of each alloy is shown in Table 1. The end faces were designated as the bonding surface and underwent plane grinding with emery paper up to grade \#2000, followed by polishing to a mirror finish using $9 \mu \mathrm{m}$ diamonds and colloidal silica. This was followed with delipidation and cleaning with aqueous sodium hydroxide $(\mathrm{NaOH})$. Furthermore, the insert metal comprised commercially available foil sheets of titanium (Ti), Aluminum-Magnesium (Al-Mg) and stainless steel (SUS). The thickness of the Aluminum-Magnesium was $0.15 \mathrm{~mm}$ while the other two metals were $0.02 \mathrm{~mm}$ thick. The chemical composition of the insert is shown in Table 2. Before bonding, the insert was delipidated and cleaned by using acetone $\left(\mathrm{C}_{3} \mathrm{H}_{6} \mathrm{O}\right)$. 
Table 1. Chemical composition of aluminum and aluminum alloy [mass\%]

\begin{tabular}{|c|c|c|c|c|c|c|c|c|}
\hline Materials & $\mathrm{Si}$ & $\mathrm{Fe}$ & $\mathrm{Cu}$ & $\mathrm{Mn}$ & $\mathrm{Mg}$ & $\mathrm{Cr}$ & $\mathrm{Zn}$ & $\mathrm{Ti}$ \\
\hline $\mathrm{A} 1070$ & 0.06 & 0.10 & 0.00 & 0.00 & 0.00 & - & 0.00 & 0.01 \\
\hline $\mathrm{A} 5052$ & 0.07 & 0.16 & 0.00 & 0.02 & 2.50 & 0.24 & 0.00 & - \\
\hline $\mathrm{A} 6061$ & 0.66 & 0.20 & 0.34 & 0.03 & 1.00 & 0.08 & 0.01 & 0.01 \\
\hline
\end{tabular}

Table 2. Properties of Intermediate materials used

\begin{tabular}{|c|c|c|}
\hline Materials & Property & Component \\
\hline $\mathrm{Ti}$ & $\mathrm{t}=0.020 \mathrm{~mm}$ & Ti: $99.5 \%$ \\
\hline $\mathrm{Al}-\mathrm{Mg}$ & $\mathrm{t}=0.015 \mathrm{~mm}$ & $\mathrm{Al}: 97 \%, \mathrm{Mg}: 3 \%$ \\
\hline $\mathrm{SUS} 304$ & $\mathrm{t}=0.020 \mathrm{~mm}$ & $\mathrm{Cr}: 18.2 \%, \mathrm{Ni}: 8.3 \%, \mathrm{Mn}: 0.84 \%, \mathrm{Si}: 0.47 \%$, Fe: Balance \\
\hline $\mathrm{Cu}$ & $\mathrm{t}=0.020 \mathrm{~mm}$ & $\mathrm{Cu}: 98 \%, \mathrm{Be}: 2 \%$ \\
\hline
\end{tabular}

\subsection{Test Equipment}

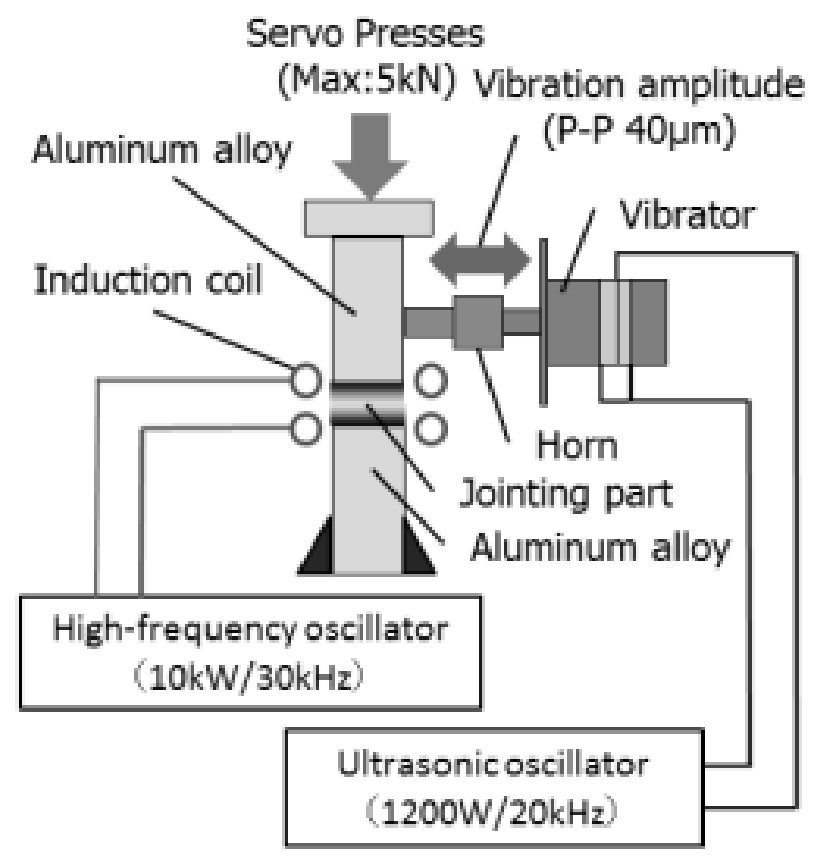

Figure 1. Test equipment schematic

An outline of the bonding equipment used in the experiment is provided in Figure 1. A high-frequency oscillator with $10 \mathrm{~kW}$ output and a frequency of $30 \mathrm{kHz}$ was used. It heats up at a rate of $16.7 \mathrm{~K} / \mathrm{sec}$ and the temperature of the joint was monitored with an infrared radiation thermometer and stabilized with a digital indicating controller. A servo press with a $5 \mathrm{kN}$ capacity was used to compress the test piece. The load cell and controller were set up to apply a constant load to the joint surfaces. Furthermore, the ultrasonic oscillator used in the bonding process had a $1200 \mathrm{~W}$ output, a frequency of 20 $\mathrm{kHz}$ and $40 \mu \mathrm{m}$ peak to peak amplitude. The oscillation amplitude was also maintained at a fixed value.

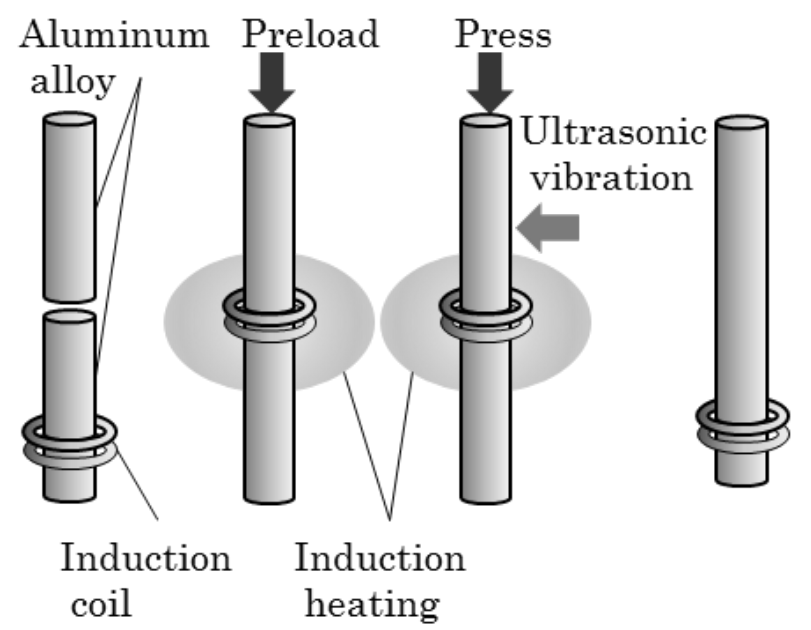

(1) Set (2) Heat (3) Vibration (4) Cooling
+Preload +Press

Figure 2. Jointing process

\subsection{Experimental Methods}

\subsubsection{Joining Method Using an Insert Metal}

The bonding method carried out in atmosphere with an insert metal is conducted as follows.

The aluminum alloys are positioned with the polished surfaces facing each other and the insert placed between the two. After a $500 \mathrm{~N}$ preload force is applied by the servo press to the joint surfaces, the bonding begins. At the same time that the joint is heated to the specified temperature by the high-frequency oscillator, the servo press subjects the combination to a $1099 \mathrm{~N}$ load. Once the specified temperature is achieved, the temperature and pressure are maintained for 360 seconds, after which the materials are air-cooled. 


\subsubsection{Ultrasonic Bonding Method}

The bonding method in atmosphere employing an ultrasonic oscillator is conducted as follows.

In the same fashion as the method using an insert metal, the polished surfaces of the two aluminum alloys are positioned facing each other. After a $500 \mathrm{~N}$ preload force is applied, the joint surface is heated by the high-frequency oscillator while the servo press subjects the pieces to a 1099 $\mathrm{N}$ load. Once the specified temperature is reached, the ultrasonic horn and V-shaped anvil are attached to the aluminum materials and ultrasonic vibrations are applied for 360 seconds, during which the pressure and temperature are maintained. Following this, the materials are air-cooled. The ultrasonic bonding process is shown in Figure 2.

\subsubsection{Measuring the Bonding Strength and Analyzing the Joint}

The strength of the bond was measured via a tension test. This test was carried out with the same specifications three times and the strength of the bond was defined as the mean value of the three results.

A scanning electronic microscope was used to observe the fracture surfaces after breaking the joint. Imagery was taken from an angle perpendicular to the fracture surface. Furthermore, the joint surfaces were cut parallel to the direction of the ultrasonic oscillations, underwent plane grinding with emery paper up to grade $\# 2000$, and were polished with $9 \mu \mathrm{m}$ diamond and colloidal silica. Following exposure to aqueous sodium hydroxide $(\mathrm{NaOH})$ for 20 seconds, the physical structure of the joint was observed with a metallographic microscope. The distribution of elements within the materials was determined by using an electron probe micro analyzer and materials subjected to the above process.

\section{Experimental Result and Consideration}

\subsection{Relationship of the Insert Metal and Bonding Strength}

The relationship between the bond strength and the different insert metals when the bond was formed at a temperature of $773 \mathrm{~K}$ is shown in Table 3. Entries showing " $x$ " indicate those which were broken by a light impact.

The results of this test were inconclusive as to the efficacy of the insert metals. Strong bonds are possible due to the potential for the inserts and aluminum alloys to form metallic compounds, however, as these bonds were formed over a short period of time and the temperature was lower than the melting point of the insert metal, this did not occur. Furthermore, the tendency of aluminum alloys to generate strong oxide layers also impedes bonding.
Table 3. Maximum tensile Load $[\mathrm{N}]$

\begin{tabular}{|c|c|c|c|c|c|}
\hline \multirow{2}{*}{ Materials } & \multicolumn{5}{|c|}{ Insert material } \\
\cline { 2 - 6 } & None & $\mathrm{Ti}$ & $\mathrm{Al}-\mathrm{Mg}$ & $\mathrm{SUS}$ & $\mathrm{Cu}$ \\
\hline $\mathrm{A} 1070$ & 4248.80 & $\times$ & $\times$ & $\times$ & 1000.00 \\
\hline $\mathrm{A} 5052$ & 2511.25 & $\times$ & $\times$ & $\times$ & 1884.37 \\
\hline $\mathrm{A} 6061$ & 2052.50 & $\times$ & $\times$ & $\times$ & $\times$ \\
\hline
\end{tabular}

\subsection{Effects of Ultrasonic Vibration on the Joint Strength}

The effects of ultrasonic vibration on joint strength are shown in Figure 3. The bond was formed at temperatures of $723^{\circ} \mathrm{K}, 773^{\circ} \mathrm{K}$ and $823^{\circ} \mathrm{K}$ and used titanium insert metals. For comparison purposes, the strength of a diffusion bond carried out in vacuum at $3.5 \mathrm{MPa}$ of pressure for one hour using a $0.02 \mathrm{~mm}$ thick titanium insert was also plotted ${ }^{2}$.

Figure 3 shows that the bond strength increases as temperature does. Additionally, it is clear that the introduction of ultrasonic vibration to aluminum alloys results in bond strength greater than that of bonds formed without such vibration.

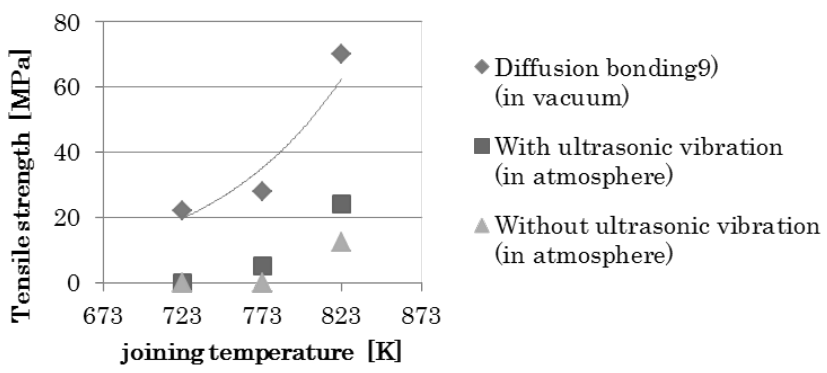

Figure 3. Relationship of tensile strength and temperature

\subsection{Effects of Ultrasonic Vibration on Metal Structures near the Junction}

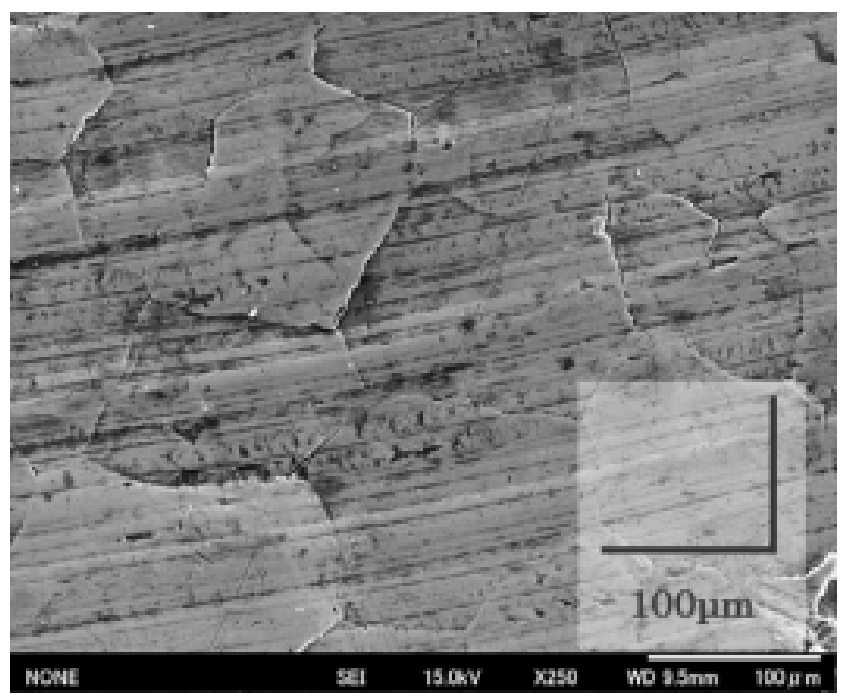

Figure 4. SEM image of the fracture surface (Without ultrasonic vibration) 


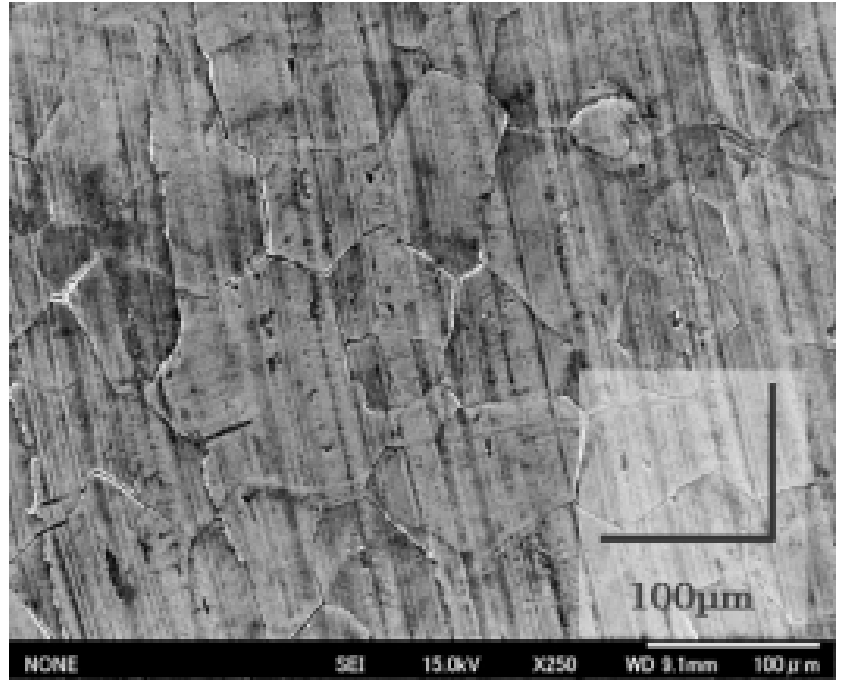

Figure 5. SEM image of the fracture surface (With ultrasonic vibration)

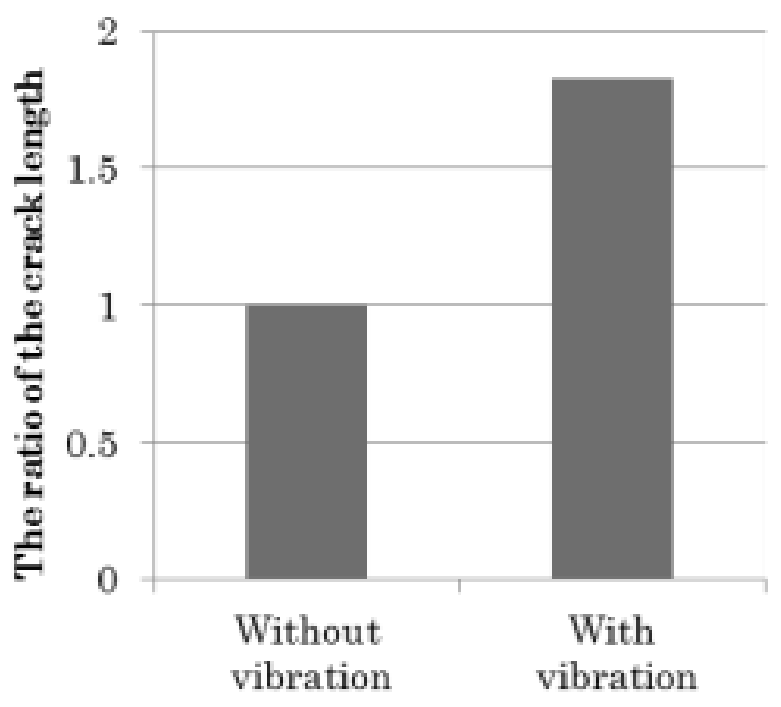

Figure 6. The ratio of crack length

Images of the fracture face from an aluminum alloy bond executed at a temperature of $823{ }^{\circ} \mathrm{K}$ are shown in Figure 4 and Figure 5. Figure 4 shows the surface that resulted when ultrasonic vibration was not used, while Figure 5 shows the surface that resulted when it was. The cracks on the fracture face were formed by the destruction of oxides on the surface of the aluminum. The lengths of the cracks shown in the photographs are provided in Figure 6. The cracks that result when ultrasonic vibration is used are 1.8 times longer than those that result when vibration is not applied.

Figure 7 is a cross section photo of a bond in which ultrasonic vibration was not used, while Figure 8 is a cross section photo of a bond in which ultrasonic vibration was used. The deep grey in the center of the photo is the titanium sheet and the lighter grey on either side is the aluminum alloy. Furthermore, the results of measurements taken of the hardness of the aluminum alloy structure at the bond are shown in Figure 9. Based on these results, it can be understood that the black structures deposited on the titanium sheet are harder than the structures located on the periphery, as Figure 8 illustrates. This is evidence that the addition of ultrasonic vibration resulted in the generation of plastic flow in the aluminum alloy structure.

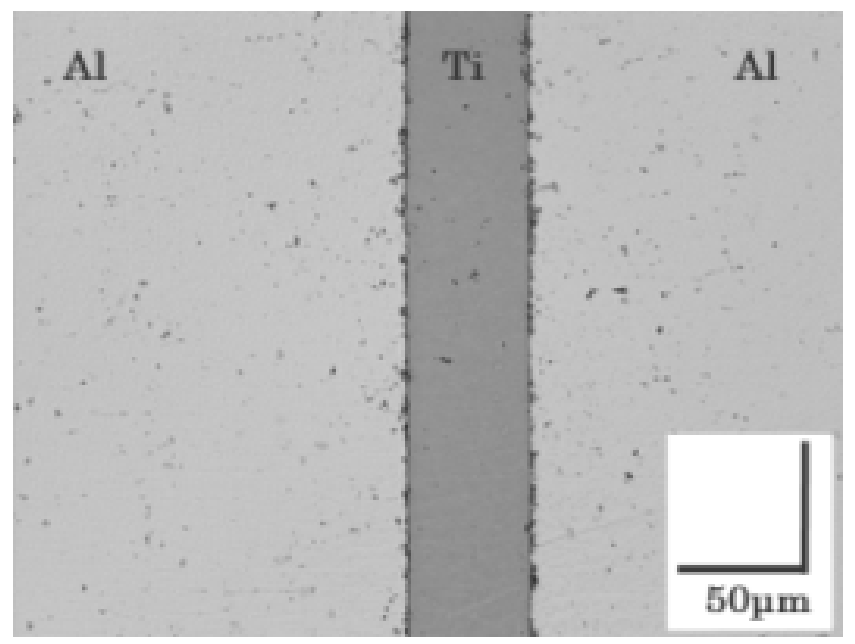

Figure 7. Microscope image of the cross section (Without ultrasonic vibration)

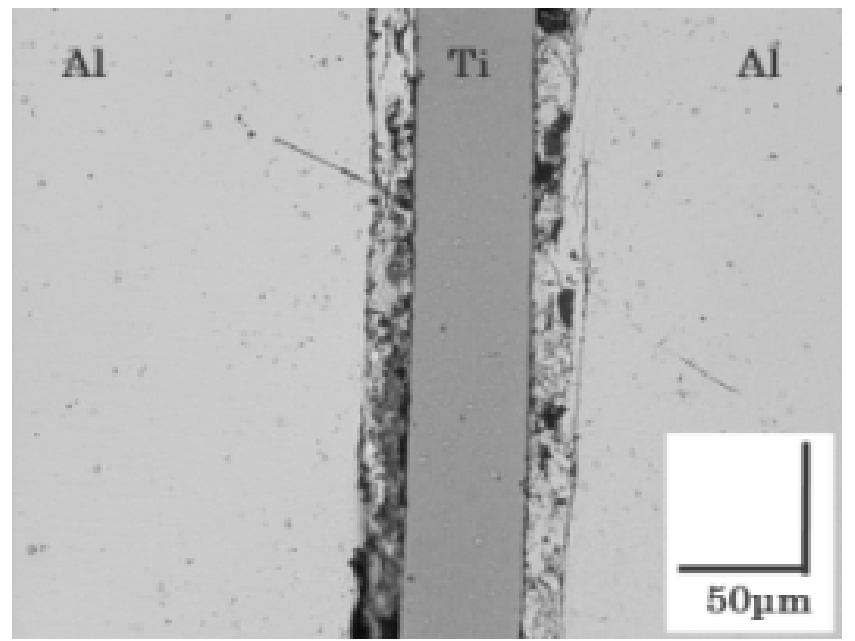

Figure 8. Microscope image of the cross section (With ultrasonic vibration)

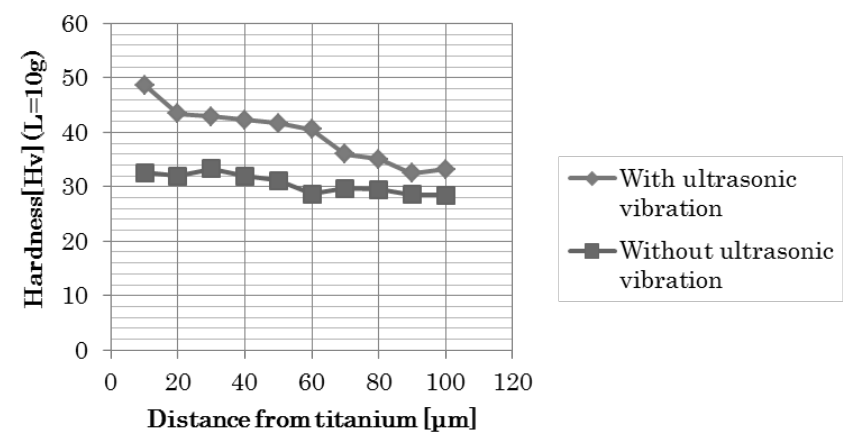

Figure 9. Relationship of Vickers hardness and distance

Next, the results of electron probe microanalysis of the cross section of the bond will be discussed. Figure 10 and Figure 12 show the EPMA results for surface analysis of a 
bond formed by diffusion bonding in vacuum and a line graph by element. Figure 11 and Figure 13 show the same, but for a bond formed by bonding in atmosphere with the addition of ultrasonic vibration. A larger amount of the element oxygen $(\mathrm{O})$ is distributed throughout the surfaces of the bond formed in atmosphere using ultrasonic vibration than throughout the surfaces of the bond formed in vacuum. Further, the bond formed in vacuum exhibits greater
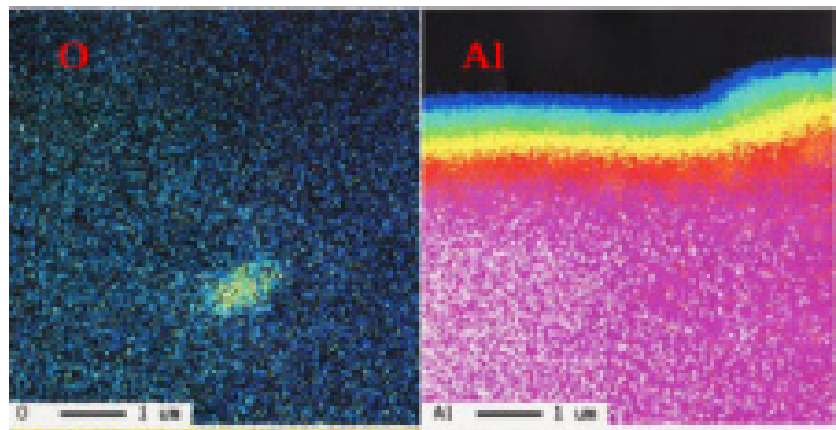

\section{Ti}
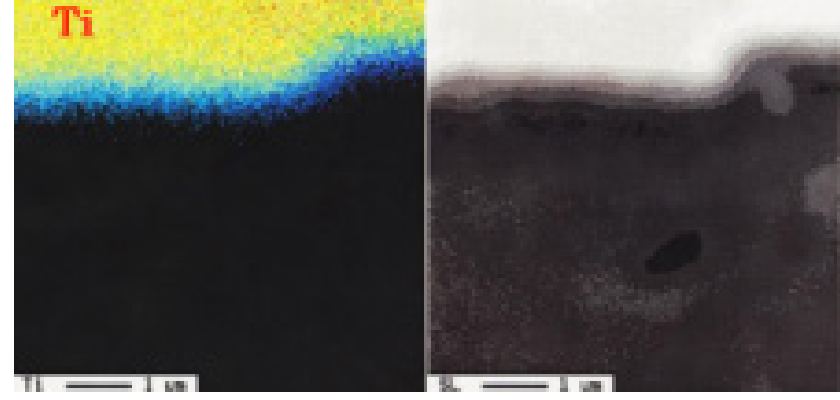

Figure 10. EPMA image (Map) (Diffusion bonding in vacuum) titanium diffusion than the bond formed in atmosphere using ultrasonic vibration. Note that there is a correlation between element diffusion and bond strength.

In short, the reason that bonds formed in atmosphere using ultrasonic vibration have weaker bond strength compared to bonds formed in vacuum is due to the high number of oxidation layers and the low level of element diffusion.

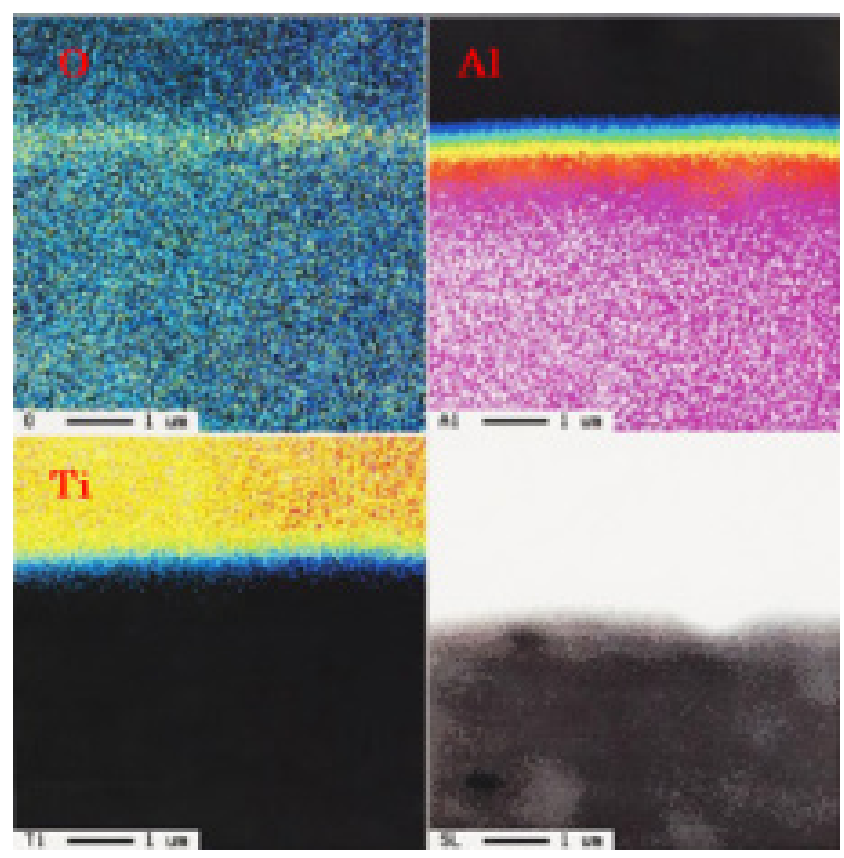

Figure 11. EPMA image (Map) (Ultrasonic bonding in atmosphere)

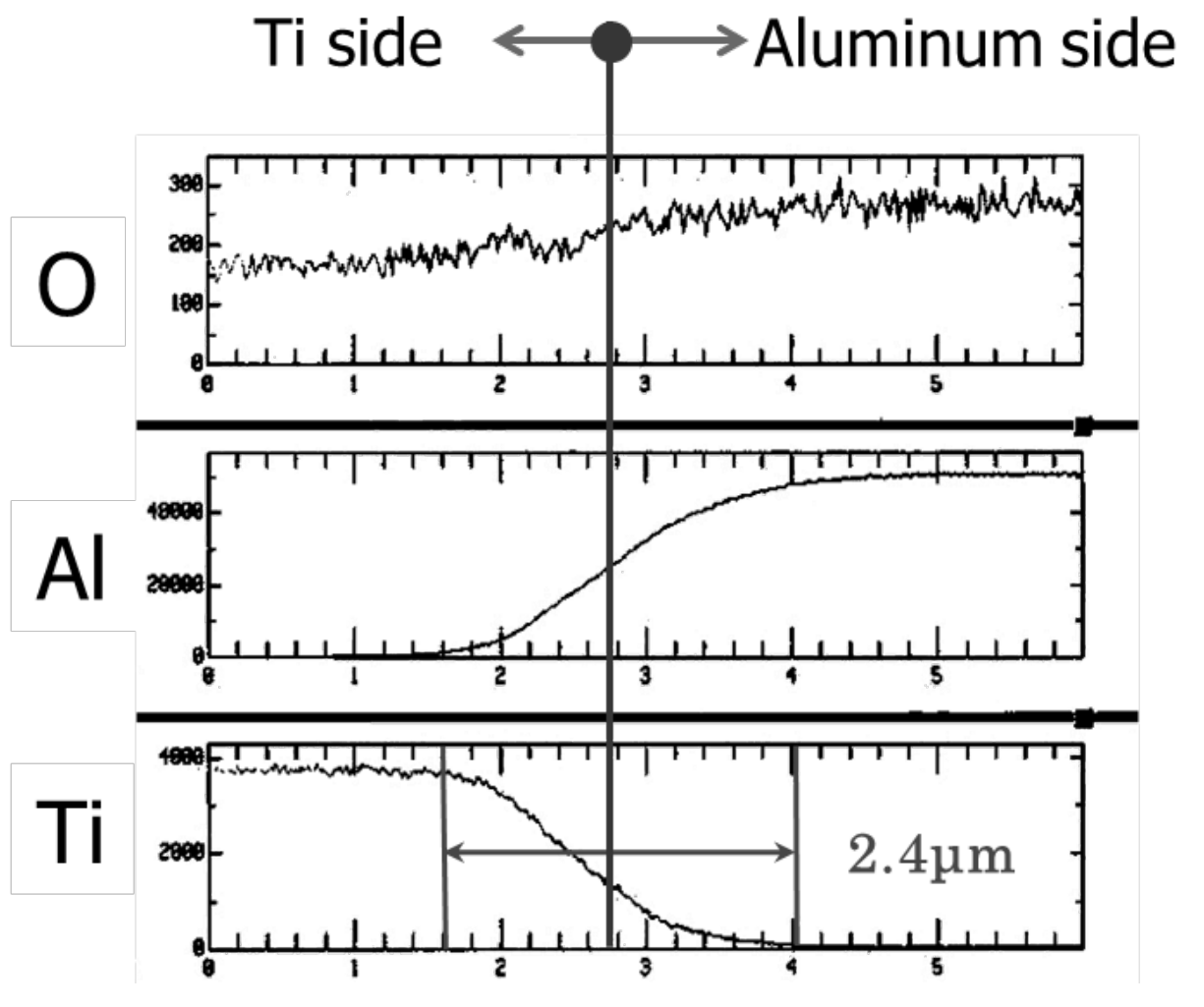

Figure 12. EPMA image (Line) (Diffusion bonding in vacuum) 


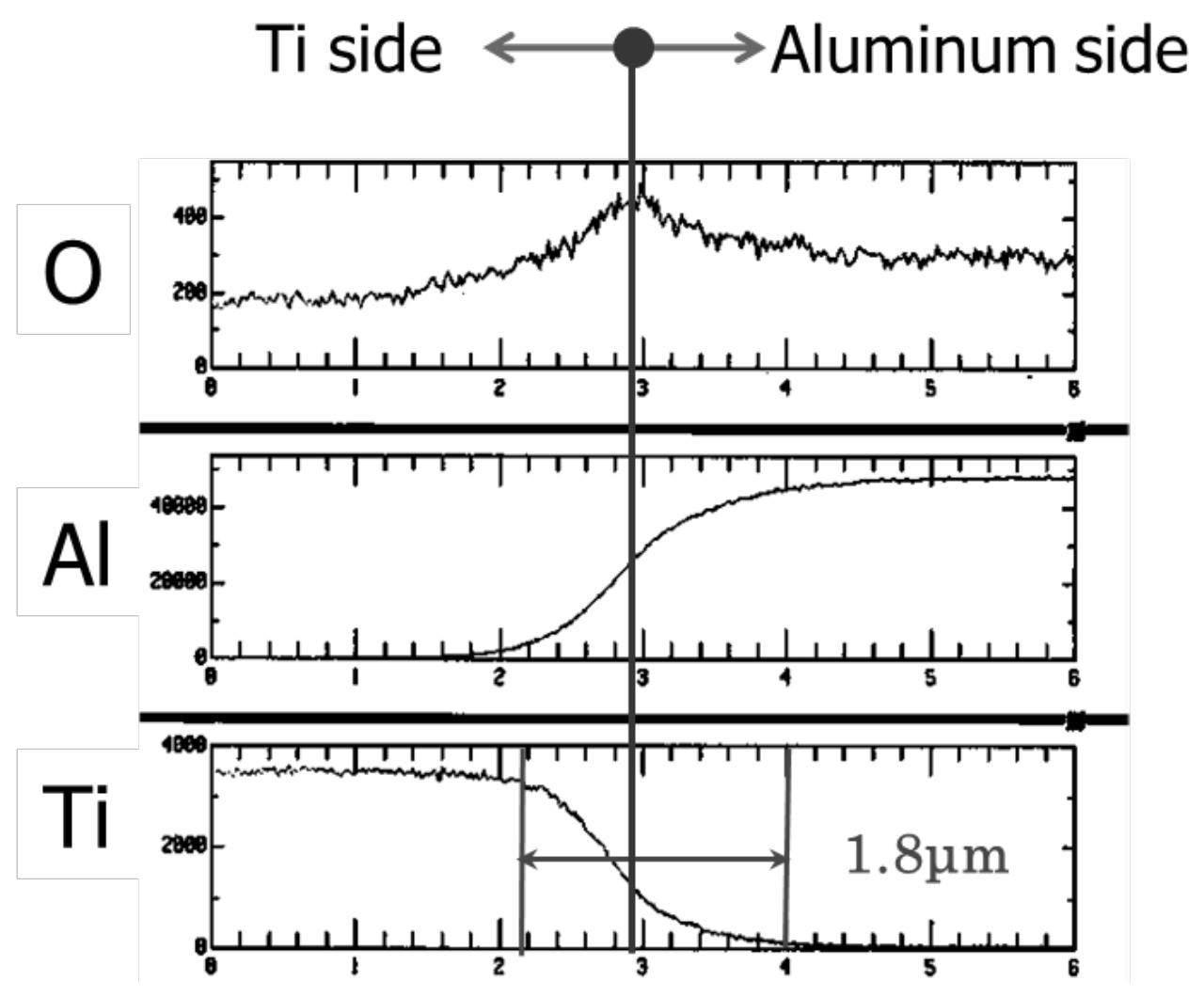

Figure 13. EPMA image (Line) (Ultrasonic bonding in atmosphere)

\section{Experiment Conclusions}

This research had the goal of developing a new method for bonding aluminum alloy in atmosphere without introducing large deformations and that can be carried out in a short amount of time. It investigated the relationship of insert metals to joint strength, the effects of ultrasonic vibration on joint strength and the effects of ultrasonic vibration on metallic structures neighboring the joint. This experiment arrived at the following conclusions.

- In cases where bonds are formed in a short period of time and the temperature is below aluminum's melting point, the oxide layer that forms on the joint surfaces of the aluminum alloy prevents intermetallic bonds from forming, reducing the potential for a successful joint.

- For bonds carried out without insert metals, the lower the tensile strength of the base metal, the easier it is to induce plastic flows, increasing the probability of forming a good bond.

- If ultrasonic vibration is applied to the joint surfaces of aluminum alloys, the strength of the resulting bond is superior to that of bonds created without using ultrasonic vibration.

- Heating the joint surfaces and adding ultrasonic vibration while the bond is under pressure promotes the destruction of the oxide layer while inducing plastic flows at the joint surfaces due to the relative motion between them.

\section{REFERENCES}

[1] Osamu Ohashi : Q\&A Diffusion bonding Sanpo Publication incorporated 1993

[2] Hisanori Okamura, Kinya Aota, Masakuni Ezumi: Friction stir welding of aluminum alloy and application to structure, Journal of Japan Institute of Light Metals, Vol. 50, No. 4 (2000), pp. 166-172

[3] Toshio Enjo: Diffusion bonding of aluminum and its alloys, Journal of Japan Institute of Light Metals, Vol. 39, No. 1 (1989), pp. 58-66

[4] Toshio Enjo, Kenji Ikeuchi, Tsutomu Horinouchi: Effect of impurities in aluminum on the diffusion bonding of aluminum to titanium, Journal of Japan Institute of Light Metals, Vol. 36, No. 3 (1986), pp. 143-151

[5] Takehiko Watanabe, Akihiko Yoneda, Atushi Yanagisawa, Shizuyo Konuma, Osamu Ohashi: Ultrasonic Welding of $\mathrm{Al}-\mathrm{Cu}$ and Al-SUS304 -Study on the Ultrasonic Welding of Dissimilar metals ( $1^{\text {st }}$ report)-, Quarterly journal of the Japan Welding Society, Vol. 17, No. 2 (1999), pp. 223-233

[6] Toshio Enjo, Kenji Ikeuchi, Hiroyuki Fujita: Effect of ultrasonic vibration on diffusion welding of aluminum, Journal of Japan Institute of Light Metals, Vol. 36, No. 8 (1986), pp. 498-506

[7] Kunio Miyazaki, Takeo Tamamura, Izumi Ochiai: Pressure Joining of Aluminum and Copper Pipes Utilizing Eutectic 
Reaction -Studies on Pressure Joining of Aluminum (Report 1)-, Quarterly journal of the Japan Welding society, Vol. 6, No. 4 (1988), pp. 486-492

[8] Preprints of the National Meeting of Japan Welding Society, Vol. 39 (1986), pp. 31-35
[9] Wako Miyagawa Osamu Saito Akio Suzuki : A study on the bonding technology of flame bonding material Development of aluminum alloy diffusion bonding method - Yamanashi Prefectural Industrial Technology Center research report Vol. 15 (2001) p 20-23 